\title{
TERAPI DIAM DALAM TASAWUF AL-GHAZALI
}

\author{
Solihin, Deden Mansur \\ UIN Sunan Gunung Djati Bandung
}

\begin{abstract}
ABSTRAK
Hujjatul Islam Imam Al-Ghazali menginterpretasikan bahaya lisan menjadi dua puluh bagian sebagaimana dilarang oleh prinsip dasar ajaran Islam (Al-Quran dan As-Sunnah). Jikalau lisan tidak dikendalikan, dapat mengakibatkan kandesnsi moral dan disintegrasi sosial dan diakhiratpun mendapatkan siksa. Maka dari itu, menurut Imam Al-Ghazali antisipasi preventifnya ialah dengan diam, karena diam (bukan diam pasif, tapi diam aktif) sangat dianjurkan oleh syariat islam, dan menghidar dari dua puluh bahaya lisan tersebut sama dengan berfikir dan berzikir sehingga pada akhirnya dapat membuahkan hasil ma'rifatullah.
\end{abstract}

\section{KATA KUNCI :}

Terapi; Diam; Zikri; Fikir; Ma'rifat

DOI: https://doi.org/10.15575/saq.v2i2.2975

\section{A. PENDAHULUAN}

Pada melinial seperti sekarang ini yang segala sesuatunya dituntut untuk serba cepat dan tepat, menjadikan banyak manusia tenggelam dalam resah dan gelisah juga putus asa. Apalagi dengan persaingan begitu tinggi, kesulitan mendera di mana-mana dalam berbagai hal. Manusia pun semakin terjebak dalam situasi kesakitan baik mental maupun spiritual.

Dalam kondisi seperti ini, peran logika yang banyak dianut oleh manusia modern sepertinya kurang pas kalau tanpa diimbangi dengan tasawuf. Tasawuf nampak sangat perlu untuk mengatasi permasalahan pada zaman sekarang ini, karena tasawuf bisa lebih mendakatkan diri kepada Allah; hati menjadi tenang, dan hidup pun bahagia.

Al-Quran sebagai kalam Allah yang disampaikan kepada Rosulullah SAW. Melalui perantaraan Malaikat Jibril, sebagai salah satu sumber utama pendidikan tasawuf, sangat penting untuk selalu dijadikan pedoman hidup yang autentik bagi umat manusia sekarang ini. Bukan hanya dalam perkembangan dan pengembangan ilmu-ilmu keislaman saja, tetapi juga sebagai inspirator di dalam melakukan ritual vertikal-horisontal sejak empat belas abad perkembangannya. Sehingga pemantapan spiritual untuk mencapai kesehatan fisik maupun batin yang sekarang terjadi di mana-mana bisa segera teratasi. Karena dengan cara demikian hati bisa menjadi tenang, apalagi bila semua urusan diserahkan kepada Allah SWT saja terutama melalui ajaran tasawuf itu sendiri.

Manusia adalah makhluk yang paling sempurna dengan panca indra yang luar biasa. Meskipun demikian, ajaran tasawuf tidaklah untuk diamalkan. Maka, tidaklah heran jikalau hanya beberapa orang saja yang bisa dikatakan sufi. Para sufi mengamalkan ajaran tasawuf biasanya dimulai dari tobat. Tobat adalah mengakui kesalahannya, memohon ampunan Nya, dan selalu menjaga diri agar tidak 
mengulanginya. Dimulai dari mengucapkan hal baik dan tidak mengucapkan hal yang buruk, karana lisan adalah alat vital yang dapat menaikan derajat manusia dan menurunkan derajat manusia. Seperti yang pernah dikatakan oleh penyair arab. Jangan engkau melaran seorang berbuat keburukan, sedang engkau mengerjakannya. ${ }^{1}$ Yang demikian itu aib besar bagimu, jika engkau mengerjakannya, lisan dapat membuat manusia terjerumus dalam neraka, begitupun didunia, lisan tidak dijaga, tidak disenangi orang. Allah SWT berfirman

$$
\text { ويل لكل همزة لَّمزة }
$$

Kecelakaan bagi setiap pengumpat lagi pencela (Q.S.Al-Humazah; 1$)^{2}$

Pembicaraan yang baik merupakan salah satu kelebihan yang baik yang dapat membantu seseorang untuk berinteraksi dengan orang lain secara efektif, mempermudah dalam membangun persahabatan dan memperkuat tali persaudaraan yang sudah lama, juga dapat meningkatkan mint dan makin mewarnai hidup. Mengapa? Karena ia bisa menjadi orang yang disukai banyak orang. Meskipun demikian, masih banyak orang yang tidak menjaga lisannya dengan baik. Rosulullah, SAW bersabda :

من كان يؤمن باله و اليوم الاخر فليقل خير الوليصمت (رواه

الترمذى عن ابى هريرة) - الته

Barang siapa yang beriman kepada Allah dan hari akhir, maka berkatalah yang baik atau diam (Muttafaq Allaih). ${ }^{3}$

Terdapat fakta bahwa diam atau menhidari perkataan yang tidak baik makin membuat hidup berwawasan. Disenangi Tuhan dan Rosul dan nanti akan menjadi penolong di akhirat; "barang siapa yang diam maka ia akan selamat" juga akan diterima hangat ketika berinteraksi dengan orang lain.

Terdapat berbagai macam penyakit dalam diri manusia. Penyakit tersebut ada yang diketahui dan ada juga yang tidak diketahui oleh penderitanya. Salah satu yang sering tidak

\footnotetext{
1 Abdul Qodir Jailani Terj. Muhammad Abdul Ghafar, Al-Ghunyah II Thalibi Thariq al-Haqq fi alKhalaq wa al-Adab al-Islamiyyah, Fiqh Tasawuf (Bandung: Pustaka Hidayah, 2003), hlm, 148.
}

diketahui oleh penderitanya adalah penyakit lisan. Karena hal tersebut banyak orang yang tidak menjaga lisannya.

Diantara sufi yang memberikan alternatif dalam mengantisipasi bahaya lidah atau penyakit lisan adalah Abu Hamid Al-Ghazali yang lebih populer adalah Hujjatul Islam. Menurutnya: terapi diam lebih menitik beratkan pada nilai-nilai spiritual keagamaan dalam bentuk akhlak mulia, di mana nilai spiritual tersebut melebar pada nilai sosial, psikologis, dan biologis dalam mencapai ridlo Allah SWT untuk bisa memperoleh kebahagiaan dunia maupun akhirat. Al-Ghazali didalam kitabnya Ihya Ulumuddin jilid kelima, membahas bahaya-bahaya lidah dan cara mengatasinya yaitu dengan cara diam.

Tujuan dalam penelitian ini adalah untuk mengetahui terapi diam menurut Al-Ghazali untuk mengantisipasi bahaya lisan, dan dapat mengetahui manfaat terapi diam menurut AlGhazali. Oleh karena itu, untuk dapat mencapai tujuan tersebut peneliti menggunakan metode deskriptf yaitu menggambarkan masalah secara kronologis (dari awal sampai akhir) dengan menelaah karya-karya Al-Ghazali.

Al-Ghazali $(450 \mathrm{H} / 1058 \mathrm{M})$ nama lengkap beliau adalah Zainuddin Hujjatul Islam Au Hamid, Muhammad bib Muhammad AlGhazali Ath-Thusi An-Naysaburi, Al-Faqih Ash-Shufi, Asy-Syafi,i Al-Asy'ari dan secara singkat dipanggil Al-Ghazali karena dilahirkan di Ghazlah, di kota Thus provinsi Kurasan,Iran sebelah utara, pada tahun $450 \mathrm{H} / 1058 \mathrm{M}$ tiga tahun setelah kaum saljuk mengambil alih kekuasaan di Baghdad.

\section{B. HASIL DAN PEMBAHASAN}

Sakit merupakan suatu keadaan yang disebabkan oleh bermacam-macam hal, bisa suatu kejadian kelainan yang dapat menitmbulkan gangguan terhadap susunan

\footnotetext{
${ }^{2}$ Al-Quran dan Terjemahan (Jakarta: KEMENAG RI, n.d.), hlm, 1101.

${ }^{3}$ Bukhari dan Muslim Terj. Hussen Bahreisj, AlJamius Shalih, Hadits Shahih (Surabaya: CV. Karya Utama, 1993), hlm, 199.
} 
jaringan tubuh baik fungsi jaringan itu sendiri maupun fungsi keseluran. ${ }^{4}$

Suatu manisfestasi dari timbulnya gangguan atas kelainan pada diri seseorang yang sehat disebut penyakit. Timbulnya penyakit pada individu dipengaruhi oleh tiga faktor utama yaitu; pertama, host atau penjamu, suatu hal yang terdapat pada individu yang dapat mengacu timbul dan berkembangnya penyakit, seperti; keturuan (gen), sistem umur, jenis kelamin, ras, status perkawinan, gaya hidup, dan lain sebagainya. Kedua, agent (bibit penyakit), suatau esensi kehadiran dan ketidak hadirannya dapat menimbulkan penyakit. Terdapat dua jenis substasi ini, biotik dan abiotik, misalnya debu, udara, dan zat kimia. Ketiga, lingkungan, yakni keseluruhan kondisi diluar individu yang mempengaruhu kehidupan dan perkembangan suatu organisme baik lingkungan fisik maupun non fisik seperti sosial budaya. Ketiga faktor tersebut saling mempengaruhi dalam

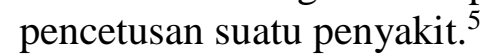

Faktor internal dalam diri yang sering diabaikan dampaakny adalah lidah. Lidah merupakan kenikmatan dari sang maha Agung, kecil lentur dan selalu tertupi oleh mulut tapi besar dosa dan ketaatannya, karena hanya dengan perkataan iman dan kufur jelas adanya. Kufur dan iman merupakan puncak ketaatan dan durhaka. Kemudia tiada sesuatu yang ada dan tiada, khaliq atau makhluk, yang dihayalkan atau yang diketahui, yang diduga atau yang dikira-kira, kecuali lidah itu dapat memperolehnya dan dihadapkan kepada lidah denganya atau tidak. Sesunggunya apa yang diperoleh oleh ilmu itu dijelaskan oleh lidah, adakalahnya dengan benar atau batil. Dan tidak ada sesuatu melainkan diperoleh oleh lidah. Ini adalah kekhususan yang tidak dapat diperoleh oleh anggota tubuh yang lain. ${ }^{6}$

Disamping itu mata tidak sampai selain kepada warna dan bentuk, telinga tidak sampai kecuali pada suara, dan tangan tidak sampai kecuali pada tubuh, begitupula anggota badan lainnya, sekuali lidah. Lidah memiliki lapangan yang luas yang tidak mempuanyai tempat menolak dan jalannya tidak mempunyai akhir juga batas. ${ }^{7}$

Lidah memiliki jalan yang lurus dalam kebaikan juga mempunyai ekor yang dapat ditarik dalam kejahatan. Barang siapa yang melepasakan kemanisan lidah dan membiarkan terkelupas talinya, niscaya setan berjalan dengannya disetiap lapangan dan mengiringnya ke tepi jurang yang menjatuhkan sehigga memaksanya kebada kebinasaan. Lidah menjatuhkan manusia atas hidupnya, kecuali oleh lisan yang dijaga. Dan tidak selamat pada kejahatan lidah kecuali orang yang mengikatlidahnya, kecuali pada sesuatu yang berguna baginya di dunia maupun di akhirat dan ia mencegah lidahnya dari setiap yang ditakuti bahayanya pada waktu sekarang dan waktu mendatang. ${ }^{8}$

Sedangkan mengenai bahaya lidah yang sudah dikonsepkan oleh Al-Ghazali ada dua puluh yaitu; pembicaraan yang berlebihan, pembicaraan panjang lebar mengenai hal yang batil, perbantahan dan perdebatan, pertengkarang, bahanya mengeluarkan suara dari kerongkongan dengan membuat-buat fasih bicaranya, berkata keji (memaki, dan lidah yang kotor), mengutuk/melaknat, nyanyian (syair tak berguna), bergurau, mengejek dan menertawakan, menyiar rahasia, janji dusta, mengumpat, mengadu domba, bahaya memuji dan berkata sesuatu hal yang tidak penting. ${ }^{9}$

Menurut Nabi Isa A.S. berbicara bai adalah dzikir, sedangkan berbicara sia-sia adalah ungkapan setan. maka patutnya umat manusia untuk menjaga lisan kerena semua tindakan dan ucapan akan dipertanggungjawabkan. Hal ini dikarenakan ucapan yang umumnya (baik yang membawa manfataan atau kerugian) akan membuka jalan

\footnotetext{
${ }^{6}$ Al-Ghazali Terj. Moh Zuhri, Ihya Ulumuddin Jilid V (Semarang: VC. Asy-Syifa, 1994), hlm, 294-295.

${ }^{7}$ Al-Ghazali Terj. Moh Zuhri, hlm, 295.

${ }^{8}$ Al-Ghazali Terj. Moh Zuhri, hlm, 295.

${ }^{9}$ Al-Ghazali Terj. Moh Zuhri, hlm, 310-494.
} 
kepada hal yang diharamkan (dilarang) dan tidak disukai. Pada intinya tidak boleh mengangab enteng segala ucapan sedikitpun. ${ }^{10}$ Karena hal tersebut dapat mencemari kesehatan jasmani maupun rohani juga akan mempengaruhi hubungan harmonis dalam interaksi di masyarakat pada umumnya.

Menjaga lisan adalah kalimat yang tepat untuk memperbaiki metode bicara dan menjaga dari bahaya yang ditimbulkan dari banyaknya bicara tersebut. Menurut ahli tasawuf menjaga lisan termasuk dalam katagori puasa rohani. Jika puasa dalam syariat menjaga makan, minum, dan berhubungan badan, maka puasa secara rohani adalah menahan dan membersihkan panca indra dan juga pikiran juga hati dari hal-hal yang diharamkan, dipertegas oleh Ali bin Abi Tholib R. A. Bahwa puasa jiwa adalah menahan dari seluru dosa dan pengosongan kalbu dari seluruh dosa dan pengosongan kalbu dari seluruh penyebab keburukan termasuk di dalamnya menjaga lisan dari perkataan yang sia-sia.

Imam Al-Ghazali memberikan solusi sebagai alternatif untuk menghindarinya, yaitu dengan cara diam. Adupun diam yang dionsepkan beliau adalah diam aktif bukan diam pasif. Diam pasif adalah diam tanpa kata supaya seseorang terhindar dari bahaya dari mulut, sedangkan diam aktif artinya berkata yang baik-baik dan yang bermanfaat saja, menjaga dari pembicaraan yang tak berguna. Belaiu juga memberikan beberapa konsep dan keutaman diam, sebagai berikut;

\section{Diam Berarti Berzikir}

Imam Al-Ghazali mengatakan dalam kitabnya Ihya Ulum ad-Din Jilid V. "Didalam pembicaraan itu terdapat bencana (bahaya) dan di dalam diam terdapat keselamatan. Karena itulah keuataman diam sanagat besar. Seiring

10 Ibnu Taimiyah, Menjaga Lisan (Jakarta: Cakrawala, 2005), hlm, 6-7.

${ }^{11}$ Al-Ghazali Terj. Moh Zuhri, Ihya Ulumuddin Jilid $V$, hlm, 308-309.

${ }^{12}$ Bukhari dan Muslim Terj. Hussen Bahreisj, AlJamius Shalih, Hadits Shahih (Surabaya: CV. Karya Utama, 1993), hlm, 199. diam terkandung keutuhan cita-cita, keabadian wibawa, kemurnian waktu untuk beribadah dan berzikir. $^{11}$

Hubungan zikir dan diam sangatah dekat, Rasulllah bersabda;

من كان يؤمن بالله و اليوم الاخر فليقل خير الوليصمت (رواه

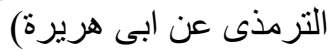

Barang siapa yang beriman kepada Allah dan hari akhir, maka berkatalah yang baik atau diam (Muttafaq Allaih). ${ }^{12}$

Secara implisit sangat jelas makna hadits diatas bahwa diam dari perkataan kotor yang dilarang oleh syariat islam seperti gosib, gibah, adu domba, fitnah, dan sebagainya adalah salah satu perbuatan yang dinyatakan dengan jelas bahwa hal tersebut sama dengan beriman kepada Allah dan hari kiamat dengan kata lain sama dengan berzikir kepada Allah SWT.

Lisan yang dikontrol dari perkataan tidak baik (baca:diam) dapat bernilai berzikir kepada Allah dan Rosul-Nya. karena menjaga hati agar tidak lupa kepada Allah, untuk memelihara hati dan anggota badan dari perbuatan maksiat, untuk menumbuhkan kecintaan kepada kebaikan, untuk memperoleh pengalaman rohani dekat dengan Allah dan untuk memperoleh ketentraman jiwa adalah bentuk dari dzikir. ${ }^{13}$

Dzikir memiliki kedudukan yang sangat penting dalam upaya mendekatkan diri kepada Allah. Dzikir menempati sentral amaliah jiwa hamba yang beriman, karena dzikir adalah seluruh gerakan hidup yang digerakkan oleh kalbu dalam fasilitas ilahi. Totalitas inilah yang nanti akan mempengaruhi aktifitas, gerak gerik, kediaman serta kontemplasi seorang hamba, dan di saat hamba tersebut istirahat dalam tidurnya. Karena totalitas inilah kaum sufi memandang dzikir mempunyai peranan penting dalam upaya mengobati penyakit rohani manusia. ${ }^{14}$

\footnotetext{
${ }^{13}$ Wahid A Muth'i, Materi Pokok Tasawuf (Jakarta: DEPAG, 1998), hlm, 73.

${ }^{14}$ M Solihin, Terapi Sufistik, Penyembuhan Penyakit Kejiwaan Prespektif Tasawuf (Bandung: Pustaka Setia, 2004), hlm, 82.
} 
Banyak orang yang memahami bahwa dzikir merupakan salah satu cara untuk terapi semua penyakit rohaniah yang dialami manusia. Walaupun yang tersirat dalam AlQuran yaitu sebagai penentram hati. Dapat difahami bahwa munculnya penyakit karena ketenangan hati. Untuk itu, kesembuhan hati merupakan awal dari kesembuhan seluruh anggota tubuh. Dalam hal ini hati dapat menenangkan hati dan jiwa orang yang sedang mengalami goncangan dan menetralisir pikiran yang sedang merasakan kepenatan. ${ }^{15}$

Sebagian ahli kedoteran jiwa meyakini bahwa penyembuhan penyakit klien dapat dilakukan lebih cepat jika memakai pengobatan keagamaan, yaitu dengan cara bangkitkan keimanan kepada Tuhan, lalu menggerakkanya ke arah pencerahan batiniah. Dengan kondisi batin yang cerah inilah pada akhirnya akan timbul kepercayaan diri bahwa Tuhan adalah satu-satunya kekuatan penyembuhan dari berbagai penyakit yang diderita. Kepercayaan ini akan menjadi daya dorong yang kuat lagi kesembuhan penyakit batin yang dialami manusia. $^{16}$

\section{Diam Berari Berfikir}

Al-Ghazali sangat menganjurkan kepada seluruh manusia untuk menjaga lisan atau diam, karena diam memiliki nilai ibadah dan mutu yang sama dengan berfikir. Menurut Imam Al-Ghazali bahwa; "Adapun hasil atau produk dari berfikir ialah berbagai ilmu, gerak hati dan amal. Tetapi produk langsungnya hanyalah ilmu saja. Memang, bila penggila ilmu telah timbul dalam hati, terjadilah suatu pengaruh dalam gerak hati dan gerak hati mengikuti pikiran. Maka berfikirlah menjadi pokok pangkal dan kunci dari segala kebaikan" ${ }^{17}$

Selain itu, belau juga mengatakan bahwa. "Periksalah lisan, apakah yang biasa dikatakan olehnya itu. Mungkin sekali ia gemar

\footnotetext{
${ }^{15}$ Solihin, hlm, 87.

${ }^{16}$ Solihin, hlm, 89.

${ }^{17}$ Al-Ghazali Terj. Moh Zuhri, Ihya Ulumuddin Jilid $V$, hlm, 309.
}

mengumpat, berdusta, menyucikan diri sendiri seolah-oleh tidak pernah keliru, suka meremehkan orang lain, banyak cakap yang tidak berguna, banyak sanda gurau yang melampaui batas, suka berbicara hal-hal yang tidak bermanfaat. Sadari pulalah bahwa semua itu termasuk hal-hal yang dibenci oleh agama. Maka tetapkan dulu dalam hatinya bahwa halhal sebagaimana diatas pula di cela oleh AlQuran dan Al-Hadits. Betapa pedihnya siksa dari perbuatan-perbuatan itu. Karenanya, maka wajiblah menghindar lisanya dari kelakuankelakuan yang terkutuk. ${ }^{18}$

Berfikir merupakan ibadah yang mengarakahkan perilaku seseorang muslim dan meningkatkan keimanannya. Apabila kegiatan berfikir yang ada dalam berbagai perasaan, kecenderungan, imajinasi, keyakinan, atifitas alam sadar atau alam bawah sadar serta kebiasaan baik dan buruk seseorang, maka cukup jelaslah bagi sebagian dari hikmah mengapa Al-Quran dan As-Sunnah banyak memberi perhatian perintah terhadap menafakuri dan merenungkan ciptaan Allah SWT di langit dan di bumi, dan mengarahkan akal pikiran pada keagungan sang pencipta dan kemuliaan sang pencipta dan kemuliaan sifatsifat-Nya. Bertafakur adalah pangkal dari segala kebaikan dan merupakan pekerjaan hati yang paling utama dan bermanfaat. ${ }^{19}$

Tafakur merupaka kunci dari segala kebaikan karena akan membentuk segala kegiatan kognitif seorang mukmin dengan dzikir kepada Allah. Bekenaan dengan keagungan-Nya, bertafakur dan memahami hikmah-hikmah yang terkandung dalam keajaiban segala ciptaan-Nya dari segala sisisisi-Nya. Tafakur merupakan pemantap keimanan dan pembeda keimanan para muttaqin. Allah Menciptakan akal, melengkapi perjalanannya dengan wahyu, kemudian memerintahkan pemiliknya untuk melihat segala ciptaan-Nya melalui tafakur, mengambil

${ }^{18}$ Al-Ghazali, Keutamaan Berfikir (Jakarta: Pustaka Amani, 1989), hlm, 15.

${ }^{19}$ Malik Badri, Tafakur Prespektif Psikologi Islam (Bandung: Rusda, 2000), hlm, 19. 
pelajaran dari segala keajaiban yang terdapat dalam ciptaan-Nya itu. ${ }^{20}$

Jelas, proses tafakur seperti ini mencakup sisi-sisi pikiran, emosi, dan persepso seseorang mukmin, ia mencakup semua kegiatan psikologis, koknitif dan spiritual. Untuk itu sulit dikatakan bahwa orang selalu berdzikir kepada Allah, namun pada saat yang sama ia sedikit bertafakur tentang penciptaan-Nya dan pada saat yang sama dikatakan sebagai orang yang tidak selalu berdzikir. Dikatakan oleh Hasan Al-Basri. "Orang-orang yang berilmu selalu menbiasakan berdzikir dalam pikiran dan pikiran dalam Berdzikir, selalu berdialog dengan hati sehingga ia berbicara penuh dengan hikmah". 21

\section{Diam Berarti Ma'rifat}

Diam adalah suatu aktivitas menghindari dari perbuatan atau perkataan yang tidak baik/kotor yang mengandung madharat di dalamnya, dan ia juga meruoakan perbuatan yang terpuji dan mengandung nilai ibadah yaitu pikir dan dzikir.

Diam timbul atau menjadi karakteristik seseorang karena hasil pemikirannya secara sistematis, teratur dan mendasar, akan bahaya lisan, sehingga perbuatan diam itu merupakan manifestasi dari fikir. Pada akhimya menumbutkan dzikir yaitu selalu ingat akan siksa Allah SWT dari bahaya lisan.

Singkronisasi fikir dan dzikir tersebut merupakan jalan yang dapat mengantarkan sescorang untuk memperoleh ma'rifat (merngenal) Allah atau dengan kata lain perbuatan diam tersebut dapat mengindikasikan fikir dan drikir sehingga membuahkan ma'rifatullah Al-Ghazali berkata."Perlu dimaklumi bahwa buah pemikiran adalah ilmu pengetahuan serta dapat memperoleh kema'rifatan yang belum pernah di hasilkan. Jikalau hati sudah memperoleh kema'rifatan yang sebelumnya belum pernah di

\footnotetext{
${ }^{20}$ Badri, hlm, 23-24.

${ }^{21}$ Badri, hlm, 24.

${ }^{22}$ Al-Ghazali Terj. Moh Zuhri, Ihya Ulumuddin Jilid
} $V$, hlm, 10. hasilkan. Jikalau hati sudah memperoleh ilmu pengetahuan, maka berubahlah keadaan hati itu. Jikalau keadaan hati sudah berubalh maka berubah pulalah amalan-amalan anggota, jadi kalau demikian, maka berfikir adalah merupakan pokok pankal untuk segala kebaikan, sebab itulah yang memindahkan yang asalnya dibenci menjadi amal dicintai itu pulalah yang menyebabkan berkembangnya ilmu pengetahuan serta membuahkan kema 'rifatan dan keuntungan." 22

Menurut Imam Ja far ash-Shadiq para ahli ma 'rifat (arif) itu ketika berada bersama orangorang hatinya selalu bersama Allah dan jika hatinya melupakan Allah selama sekejap mata saja, ia akan mati karena merindukan-Nya. Ahli ma 'fifat adalah kekasih Allah, penyimpan rahasia-rahasia-Nya, gudang bagi cahayacahaya Nya, bukti belas kasih-Nya kepada ciptaan-Nya, sarana bagi ilmu-ilmu-Nya dan ukuran bagi karunia dan keadilan-Nya. Ia tidak membutuhkan siapapun, atau suatu tujuan apapun atau dunia ini. Ia tidak mempunyai kawan dekat kecuali Allah, atau hanya dapat berbicara, bergerak, bernafas karena Allah, bersama Allah, dan dari Allah sebab ta sering mendatangi taman kesucian-Nya dan diperkaya oleh paling muka untuknya. Ma'rifat adalah sebuah akar, dan cabangnya adalah iman. ${ }^{23}$

Dari literatur yang diberikan tentang ma'rifat, ma'rifat berarti mengetahui Tuhan dari dekat, schingga hati sanubari dapat melihat Tuhan Oleh karena itu orang- orang sufi terutama al-Ghazali mengatakan:

1) Kalau mata yang terdapat dalam hati sanubari akan tertutup, dan seketika itu yang dilihatnya hanya Allah

2) Ma'rifat adalah cermin, kalau seorang arif melihat kecermin itu yang akan dilihatnya hanyalah Allah.

3) Yang dilihat orang arif (ma'rifat) baik sewaktu tidur maupun sewaktu terjaga hanya Allalh

\footnotetext{
${ }^{23}$ Imam Ja'far Ash-Shodiq, Lentera Ilahi, 99 Wasiat Imam Ja'far Ash-Shodiq (Bandung: Mizan, 1995), hlm, 1993.
} 
4) Sekiranya ma'rifat mengambil bentuk materi semua orang yang melihat padanya akan mati karena tak tahan melihat kecantikan serta keindahanNya dan semua cahaya akan menjadi gelap disamping cahaya keindahaNnya yang gilang gemilang. ${ }^{24}$

\section{KESIMPULAN}

Terapi diam dalam tasawuf Al-Ghazali adalah mengontrol dan menjaga lisan berbicara yang dilarang oleh ajaran dasar Islam (AlQur'an dan As-Sunnah) yaitu sebagaimana yang dikonsepsikan/dinterpretasikan olehnya menjadi dua puluh bagian. seperti menggunjing, mengadu domba, bicara berlebihan dan fitnah sebagainya.

Terapi diam yang dikonsepsikan oleh AlGhazali terbagi menjadi dua ba yaitu: terapi diam pasif dan terapi diam aktif. Adapun terapi diam pasif yaitu membisu atau diam dari dua puluh bahaya lisan yang dikonsepsikan oleh Sementara terapi diam aktif yaitu dianjurkan atau diperbolehkan untuk berbicara selain dari dua puluh bahaya lisan tersebut di atas. Seperti amar ma 'ruf munkar.

Adapun manfaatnya dari terapi diam yang dikonsepsikan oleh Al-Ghazali adalah sebagai berikut; Supaya selamat di dunia maupun di akhirat, Agar bersosialisasi dengan orang lain baik dan menghasilkan manfaat.

\section{DAFTAR PUSTAKA}

A Muth'i, Wahid. Materi Pokok Tasawuf. Jakarta: DEPAG, 1998.

Al-Ghazali. Keutamaan Berfikir. Jakarta: Pustaka Amani, 1989.

Al-Ghazali Terj. Moh Zuhri. Ihya Ulumuddin Jilid V. Semarang: VC. Asy-Syifa, 1994.

Al-Quran dan Terjemahan. Jakarta: KEMENAG RI, n.d.

Ash-Shodiq, Imam Ja'far. Lentera Ilahi, 99
Wasiat Imam Ja'far Ash-Shodiq. Bandung: Mizan, 1995.

Badri, Malik. Tafakur Prespektif Psikologi Islam. Bandung: Rusda, 2000.

Bukhari dan Muslim Terj. Hussen Bahreisj. AlJamius Shalih, Hadits Shahih. Surabaya: CV. Karya Utama, 1993.

Nasution, Harun. Filsafat dan Mistisisme dalam Islam. Jakarta: Bulan Bintang, 1995.

Qodir Jailani Terj. Muhammad Abdul Ghafar, Abdul. Al-Ghunyah II Thalibi Thariq alHaqq fi al-Khalaq wa al-Adab alIslamiyyah, Fiqh Tasawuf. Bandung: Pustaka Hidayah, 2003.

Sholeh, Moh. Agama sebagai Terapi, Telaah Menuju Ilmu Kedokteran Holistik. Yogyakarta: Pustaka Pelajar, 2005.

Solihin, M. Terapi Sufistik, Penyembuhan Penyakit Kejiwaan Prespektif Tasawuf. Bandung: Pustaka Setia, 2004.

Taimiyah, Ibnu. Menjaga Lisan. Jakarta: Cakrawala, 2005.
${ }^{24}$ Harun Nasution, Filsafat dan Mistisisme dalam Islam (Jakarta: Bulan Bintang, 1995), hlm, 75-76. 